\title{
Knowledge-Attitude-Practice of Medical Students on Expired Drugs
}

\author{
Lou Pengyu, Wang Wei, Li Yunwei* \\ College of Public Health and Management, Weifang Medical University, Weifang, China \\ Email address: \\ loupy@wfmc.edu.cn (Lou Pengyu),wang_w2006@126.com (Wang Wei), liyunwei1982@126.com (Li Yunwei) \\ ${ }^{*}$ Corresponding author
}

\section{To cite this article:}

Lou Pengyu, Wang Wei, Li YunWei. Knowledge-Attitude-Practice of Medical Students on Expired Drugs. International Journal of Vocational Education and Training Research. Vol. 5, No. 1, 2019, pp. 29-32. doi: 10.11648/j.ijvetr.20190501.15

Received: March 19, 2019; Accepted: May 10, 2019; Published: June 11, 2019

\begin{abstract}
Purpose this study provides reference for solving the problem of drug waste and reforming medical education. Methods Stratified random sampling was employed to recruit 998 Senior students of three medical colleges. The questionnaire included 12 items of basic knowledge of expired drugs, 4 items of attitude towards expired drugs and 3 items of behavior on reducing expired drugs. Results The valid rate of all questionnaires was $83.17 \%$. $43.29 \%$ of students knew a large number of expired drugs produced in China every year. Among the basic knowledge items of expired drugs, the awareness rate of toxicity hazards of expired drugs was the highest, and the awareness rate of recycling knowledge of expired drugs was the lowest. $62.52 \%$ agreed that the production of expired drugs was inevitable, $74.35 \%$ were willing to regulate their own behavior after knowing the harm of expired drugs. The sources of expired drug knowledge were internet $(35.57 \%)$, university-related courses $(30.86 \%)$, health education materials $(28.96 \%)$, TV/radio $(28.56 \%)$, internship teachers $(12.42 \%)$, internship unit training $(8.52 \%)$ and family members $(7.52 \%)$. Conclusion Three medical college students had low awareness of expired drugs, so it is necessary to adjust the content and mode of pharmaceutical teaching, strengthen the training of social responsibility in the period of internship, introduce service learning theory into social practice activities.
\end{abstract}

Keywords: Medical Students, Expired Drugs, Pharmaceutical Education

\section{Introduction}

According to the White Paper on the Recovery of Expired Drugs in Chinese Families (2004-2014), published in 2014, about $78.6 \%$ of families in China had small medicine boxes [1]. Affected by social development and medication habits, the stockpile of small medicine boxes in families was increasing. there were 215 grains of expired medicines in every household in China. The expired medicines caused 15,000 tons waste every year. The waste of medicines had become a growing concern of the public [2]. To alleviate or solve this problem, the society, doctors and patients need to work together. Medical workers who provide medical and pharmaceutical services for patients will undoubtedly play an important role. Most students in medical colleges will be engaged in the work closely related to drug use after graduation. Their knowledge, concept and professional standards of drug use will affect patients' cognitive level of drug use and drug purchasing behavior. Their cognition, attitude and behavior towards expired drugs will affect the time and extent of solving drug waste problems in the future. In order to understand the knowledge, attitude and behavior of medical students towards expired drugs, and provide reference for alleviating drug waste and improving pharmaceutical education, a survey was conducted in three medical colleges in Shandong Province from October to December 2016.

\section{Object and Methods}

\subsection{Object}

Using stratified random sampling method, three universities including Qingdao University Medical Department, Weifang Medical College and Binzhou Medical College, were selected among which senior medical students and pharmaceutical students who had drug use experience were chosen. 1,200 questionnaires were distributed, and 998 questionnaires were effectively returned, with an valid rate of 
83.17\%. Among them, $290(29.06 \%)$ were in the Medical Department of Qingdao University, 372 (37.27\%) in Weifang Medical College, 336 (33.67\%) in Binzhou Medical College, $748(74.95 \%)$ in clinical specialty, $147(14.73 \%)$ in pharmacy and $103(10.32 \%)$ in pharmaceutical marketing.

\subsection{Methods}

Combining with the research objectives, using the methods of literature review and historical data analysis, the research group designed the questionnaire by itself. The content of the survey mainly includes the demographic variables of the respondents, the cognition of expired drugs (knowledge, identification, harm caused by improper disposal, treatment, etc.), the attitude towards expired drugs, and the influence of expired drugs on their professional behavior. The questionnaire was filled out anonymously on the basis of informed consent of the respondents. The questionnaires that lacked basic information and did not answer completely (more than 3 missing items) were used as the criteria for evaluating the invalid questionnaires to screen the returned questionnaires.

\subsection{Statistical Analysis}

EpiData2.0 was used for the double entry of database. SPSS 18 software was used for statistical processing of data. The basic information of the respondents and descriptive analysis of Knowledge-attitude-practice of expired drugs were made.

\section{Results}

\subsection{Awareness and Access to Knowledge of Expired Drugs}

The results showed that $43.29 \%$ of the students knew that a large number of expired drugs were produced in China every year. Among the basic knowledge items of expired drugs, the awareness rate of toxicity hazards of expired drugs was the highest, and the awareness rate of recycling knowledge of expired drugs was the lowest. As shown in Table 1. The sources of expired drug knowledge were internet $(35.57 \%)$, university-related courses $(30.86 \%)$, health education materials $(28.96 \%)$, TV/radio (28.56\%), internship teachers $(12.42 \%)$, internship unit training $(8.52 \%)$ and family members $(7.52 \%)$.

Table 1. Awareness of expired drugs.

\begin{tabular}{lll}
\hline Basic Knowledge Items of Expired Drugs & $\begin{array}{l}\text { Awareness } \\
\text { num }\end{array}$ & $\begin{array}{l}\text { Awareness } \\
\text { Rate (\%) }\end{array}$ \\
\hline $\begin{array}{l}\text { The validity period is affected by storage } \\
\text { conditions }\end{array}$ & 735 & 73.7 \\
$\begin{array}{l}\text { Drug expiration should be distinguished by } \\
\text { dosage form }\end{array}$ & 482 & 48.3 \\
$\begin{array}{l}\text { Shortened validity period after opening } \\
\begin{array}{l}\text { Drugs beyond their expiry date are inferior } \\
\text { The expired drugs produced in the process of } \\
\text { production, sale and use are hazardous wastes }\end{array}\end{array}$ & 585 & 58.6 \\
$\begin{array}{l}\text { The efficacy of expired drugs decreases and } \\
\text { toxicity increases }\end{array}$ & 969 & 59.7 \\
$\begin{array}{l}\text { Improper disposal of expired drugs pollutes the } \\
\text { environment }\end{array}$ & 729 & 79.4 \\
\hline
\end{tabular}

\begin{tabular}{|c|c|c|}
\hline Basic Knowledge Items of Expired Drugs & $\begin{array}{l}\text { Awareness } \\
\text { num }\end{array}$ & $\begin{array}{l}\text { Awareness } \\
\text { Rate (\%) }\end{array}$ \\
\hline $\begin{array}{l}\text { Expired drugs have the risk of re-packaging and } \\
\text { re-marketing }\end{array}$ & 224 & 22.4 \\
\hline $\begin{array}{l}\text { How to deal with and recover expired drugs is not } \\
\text { stipulated in the Drug Administration Law }\end{array}$ & 259 & 25.9 \\
\hline $\begin{array}{l}\text { Household expired medicines should be included } \\
\text { in specialized collection and destruction systems }\end{array}$ & 301 & 30.2 \\
\hline $\begin{array}{l}\text { Know how to handle different types of expired } \\
\text { drugs }\end{array}$ & 297 & 29.8 \\
\hline Know how to recycle expired drugs & 157 & 15.7 \\
\hline
\end{tabular}

\subsection{Attitudes of Respondents to Expired Drugs}

624 people $(62.52 \%)$ agreed that the production of expired drugs was inevitable, 781 people $(78.26 \%)$ agreed that a large number of expired drugs were harmful to people, and 506 people $(50.71 \%)$ agreed that their occupation played a great role in reducing drug waste. As shown in Table 2.

Table 2. Attitudes of respondents to expired drugs.

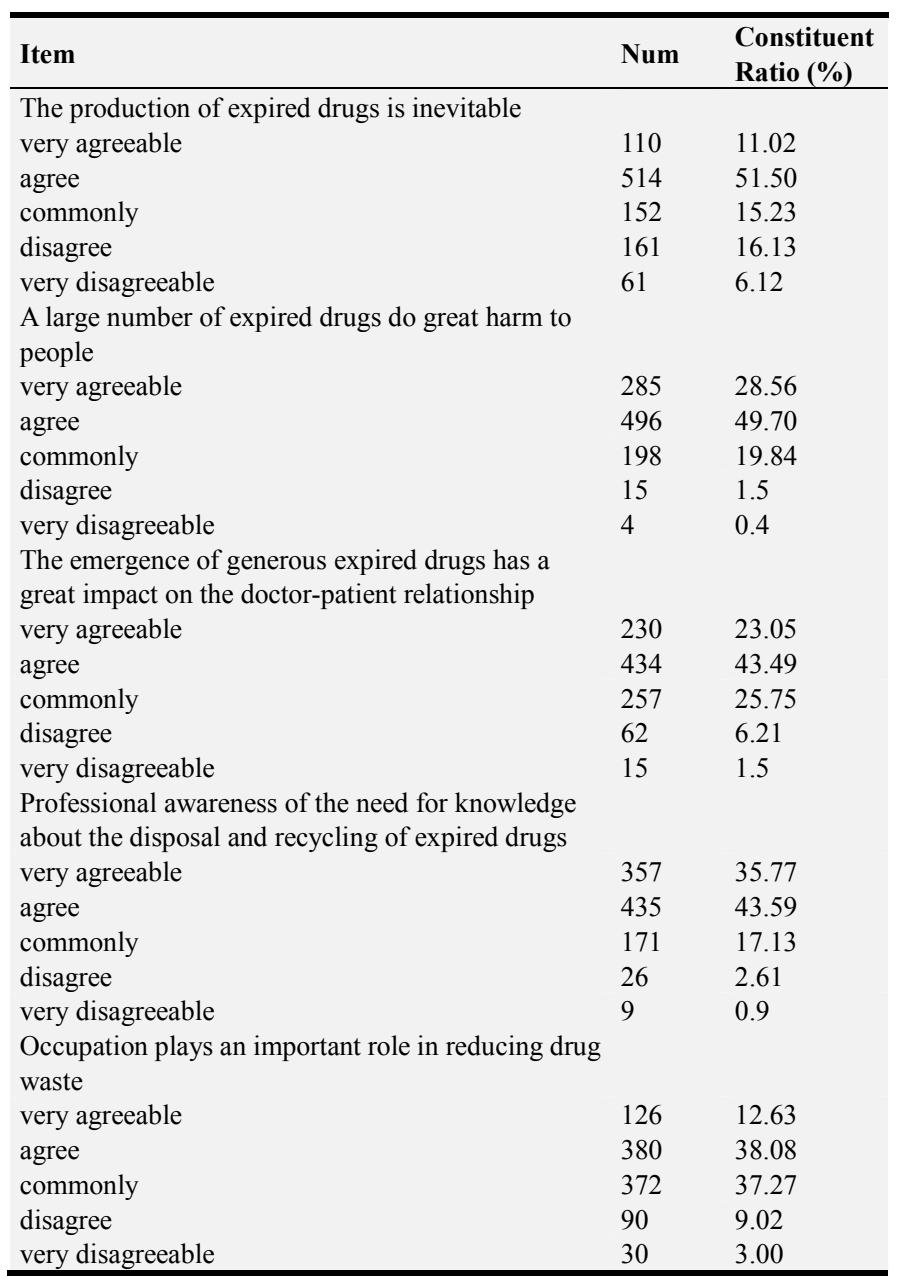

\subsection{Relevant Behavior of Respondents to Expired Drugs}

742 people $(74.35 \%)$ were willing to regulate their own practice after knowing the harm of expired drugs, 817 people $(81.86 \%)$ were willing to actively participate in the daily health management of residents to reduce drug waste, 645 people $(64.63 \%)$ were willing to actively inform patients of 
expired drug knowledge to reduce drug waste. As shown in Table 3.

Table 3. Relevant Behavior of expired Drugs.

\begin{tabular}{lll}
\hline Item & Num & $\begin{array}{l}\text { Constituent } \\
\text { ratio (\%) }\end{array}$ \\
\hline $\begin{array}{l}\text { Willing to regulate their own practice after } \\
\text { knowing the harm of expired drugs }\end{array}$ & \\
$\begin{array}{l}\text { very agreeable } \\
\text { agree }\end{array}$ & 262 & 26.25 \\
commonly & 480 & 48.10 \\
disagree & 208 & 20.84 \\
very disagreeable & 38 & 3.81 \\
Willing to actively participate in residents' daily & 10 & 1.00 \\
health management to reduce drug waste & & \\
very agreeable & 395 & 39.58 \\
agree & 422 & 42.28 \\
commonly & 158 & 15.83 \\
disagree & 16 & 1.6 \\
very disagreeable & 7 & 0.71 \\
Willing to actively inform patients about expired & & \\
drug knowledge to reduce drug waste & 316 & 31.66 \\
very agreeable & 329 & 32.97 \\
agree & 242 & 24.25 \\
commonly & 71 & 7.11 \\
disagree & 40 & 4.01 \\
very disagreeable & & \\
\hline
\end{tabular}

\section{Discussion}

Rich knowledge of medication is very important for guiding students to cultivate good medical ethics and rational drug prescription behavior, and it is also great significance for doctors to disseminate rational drug use behavior to patients [3]. This study showed that students' knowledge about the harmful effects of improper disposal on expired drugs was relatively inadequate, with correct rate of $43.29 \%$. The awareness rate of producing large quantities of expired drugs in China was less than 50\% annually, and the awareness rate of knowledge about the recovery of expired drugs was the lowest $(15.73 \%)$. The main reason was that the curriculum of pharmacy in colleges and universities of China mainly focused on the basic course of chemical pharmacy specialty [4], ignoring the humanistic education of pharmacy. Pharmacology and clinical pharmacology accounted for too little of the total school hours of medical education [5]. Pharmaceutical care and other ethical knowledge were not paid enough attention, and the content involved less [6]. Among them, the knowledge related to expired drugs was even less. We can improve theoretical study by adjusting the teaching content of pharmacy. It is suggested that ADR and rational drug use should be included in the professional knowledge curriculum system [7], and that courses of pharmacy administration and Pharmacy Ethics should be set up to strengthen the pharmacy humanities education of medical students [8]. It is suggested that the traditional education and teaching methods should be changed, and the current policies and social hot spots related to medicine and pharmacy should be discussed in the form of class, so that students can internalize the knowledge of medical and
Pharmacy Ethics into their own quality, character and working attitude. Only when we feel the important role of humanistic knowledge and spirit in solving practical problems can we fundamentally change the traditional education concept and make the humanistic education of pharmacy adapt to the requirements of the times [9].

Correct and positive attitudes towards expired drugs play a role in promoting the standardization of occupation practices to a certain extent. This study showed that 624 people agreed the unavoidable occurrence of expired drugs, 217 people did not think that a large number of expired drugs would cause great harm to people, 334 people did not think that a large number of expired drugs would affect doctor-patient relationship, 120 people did not agree with the reduction of occupational involvement in subjective barriers. The above situation showed that some students did not pay enough attention to the problem of expired drugs and waste of drugs. The reason was that medical colleges neglected the cultivation of professional social responsibility in the process of strengthening humanistic education and promoting professional ethics [10]. It is suggested that social responsibility should be strengthened in the period of internship. Expanding the forms of humanistic quality for medical students and strengthening the standardized training of resident physicians (pharmacists) [11]. In the clinical practice stage, the teaching content is no longer limited to follow-up and case preaching, and the professional social responsibility of students is enhanced by the humanistic teaching methods of medical (pharmacist) teachers with profound humanistic knowledge and good humanistic literacy, such as medical ethics advanced deeds report conference [12-13].

Altruistic behavior and social behavior of medical students should be the focus of moral education [14]. 742 people were willing to regulate their occupation practice, 817 people were willing to participate actively in the daily health management of residents to reduce drug waste, 645 people were willing to actively inform patients of the knowledge of expired drugs to reduce drug waste. The above showed that most respondents were willing to regulate their behavior and participate actively when they were aware of their responsibilities. The introduction of service-based learning theory into social practice will increase the effect of education [15]. In order to enable medical students to contact with society and patients through multiple channels, angles and levels, and cultivate their awareness of public health services and social services, it is suggested to formulate practical objectives integrating curriculum, service and reflection, to adopt the socialized practice mode of family, school, society and government, and to design health social investigation, contact community health propaganda, and rescue vulnerable groups.

\section{Conclusion}

Medical students in the three universities had low awareness of expired drugs. At the stage of basic knowledge learning and practical learning, the knowledge of expired 
drugs was less involved. In order to improve medical students' awareness of expired drugs and cultivate their professional humanistic literacy in an all-round way, higher medical education should pay enough attention to the humanistic literacy of pharmacy, carry out targeted courses, lectures, training or practical activities, and explore ways to alleviate or solve the problem of drug waste by improving the awareness of medical service providers of expired drugs in the long run.

\section{Acknowledgements}

This research was financially supported by the 2016 medical education research project (Grant NO. 2016B-RW044, 2016B-FF073).

\section{References}

[1] Sang Shenggao. Expect to Achieve "National Top-level Design" for Expired Drug Recycling. [EB/OL]. [2015-02-27]. http://pinglun.iqilu.com/yuanchuang/2015/0227/2318094.shtm 1 (In Chinese).

[2] China Reporting Network. Current situation of disposal of expired drugs in China. [EB/OL] [2014-05-07]. http://market.chinabaogao.com/yiyao/05GS4392014.html (In Chinese).

[3] Wang Chunwei. Preliminary Exploration of Rational Drug Use Education in Clinical Undergraduate Teaching [J]. Clinical rational drug use. 2015, 8 (9): 6-7 (In Chinese).

[4] Lei Yingjie, Ding Mei, Liu Yuming. Discussion on Improving the Humanistic Care Ability of Pharmaceutical Students [J]. Pharmaceutical Education, 2017, 33 (4): 1-4 (In Chinese).

[5] Li Xiao Ping. Reflections on the Teaching Reform of Pharmacology for Clinical Medicine Major [J]. Journal of Shanxi Medical University (Basic Medical Education Edition). 2003, 5 (6): 594-595 (In Chinese).

[6] Lan Li UN. Thoughts on Improving the Concept and Teaching Effect of Preventive Medicine for Clinical Medical Students
[J]. Public Health Management in China. 2016, 32 (1): 73-76 (In Chinese).

[7] Zhao Yuxiang, Ding Xiaoli, Chen Kai, etc. Thoughts on Strengthening the Training of Medical Students' Knowledge of Adverse Drug Reactions and Rational Drug Use [J]. Clinical rational drug use. 2014, 7 (7): 171-172 (In Chinese).

[8] Sun Ting, Liu Jiang, Zhang Junzhen, etc. Practice of Strengthening Pharmaceutical Ethics Education of Clinical Medicine Students [J]. Chinese Medical Ethics. 2015, 28 (5): 765-768 (In Chinese).

[9] Zhang Yuqiang, Cao Heshe. Research on the Current Situation and Path of Humanistic Quality Training of Pharmaceutical College Students [J]. Pharmaceutical Education, 2016, 32 (4): 30-33 (In Chinese)

[10] Zhang Haidong, Zhang Qinfeng, Li Wei, etc. Adjusting and Optimizing the Course System of Medical Specialty and Cultivating the New Concept of Preventive Health Care for Medical Students [J]. Higher Medical Education in China. 2010, 23 (6): 85-86 (In Chinese).

[11] Jiang Lanshu, Sun Hongliang, Gong Fuqing. Analysis of the effectiveness of medical humanistic spirit cultivation for medical students $[\mathrm{J}]$. Medicine and Philosophy. 2014, 35 (6): 52-60 (In Chinese).

[12] Du Zhizheng. Training Objectives of Medical Students and Teaching of Humanistic Medicine $[\mathrm{J}]$. Medicine and Philosophy, 2015, 36 (6): 4-6 (In Chinese).

[13] Lei Hailu, Zhang Jinhua, Yao Guiying, et al. Investigation and analysis of the current situation of humanistic care consciousness and ability of medical students [J]. China Higher Medical Education. 2012, 25 (1): 36-37 (In Chinese).

[14] Wang Rui. A comparative study of altruistic behavior between doctors and medical students [D]. Nanjing Normal University, 2014: 7-10 (In Chinese).

[15] Kang Junbiao. Exploration of the social practice model of medical students based on service-based learning theory [J]. Journal of Nanjing University of Traditional Chinese Medicine. 2016, 17 (3): 207-210 (In Chinese). 